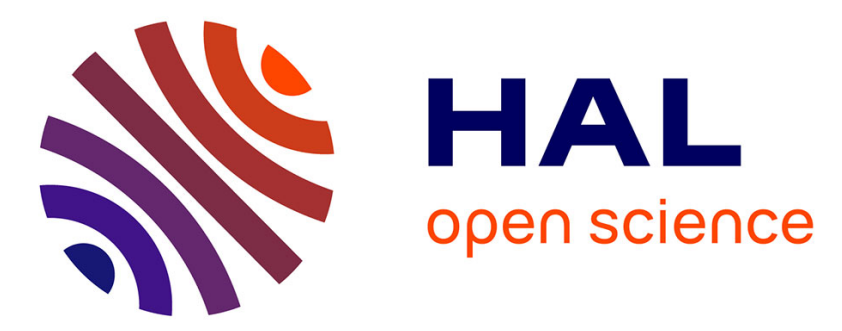

\title{
An Ad'hoc network simulator based on an optimized semi-deterministic channel characterization
}

Rudy Delahaye, Pierre Combeau, Anne-Marie Poussard, Yannis Pousset, Rodolphe Vauzelle

\section{- To cite this version:}

Rudy Delahaye, Pierre Combeau, Anne-Marie Poussard, Yannis Pousset, Rodolphe Vauzelle. An Ad'hoc network simulator based on an optimized semi-deterministic channel characterization. European Conference on Wireless Technology (ECWT), Oct 2005, Paris, France. pp.177-180, 10.1109/ECWT.2005.1617684 . hal-00349077

\section{HAL Id: hal-00349077 https://hal.science/hal-00349077}

Submitted on 27 Apr 2021

HAL is a multi-disciplinary open access archive for the deposit and dissemination of scientific research documents, whether they are published or not. The documents may come from teaching and research institutions in France or abroad, or from public or private research centers.
L'archive ouverte pluridisciplinaire HAL, est destinée au dépôt et à la diffusion de documents scientifiques de niveau recherche, publiés ou non, émanant des établissements d'enseignement et de recherche français ou étrangers, des laboratoires publics ou privés. 


\title{
An Ad-hoc network simulator based on an optimized semi-deterministic channel characterization
}

\author{
Ruddy Delahaye, Pierre Combeau, Anne-Marie Poussard, Yannis Pousset, Rodolphe Vauzelle \\ University of Poitiers, SIC, FRE CNRS 2731, Bd Marie et Pierre Curie, 86360 Chasseneuil du Poitou, France \\ \{delahaye, combeau, poussard, pousset, vauzelle\}@sic.sp2mi.univ-poitiers.fr
}

\begin{abstract}
Classical studies on Ad-hoc networks use statistical models to characterize the physical layer of each radio link. In this paper we present an original simulator allowing to quantify these links by a statistical or deterministic channel characterization. The main issue of the deterministic approaches is the computation time. So, we consider for our study an optimized semi-deterministic characterization of the propagation channel. Finally, we quantify each radio link of an Ad-hoc network by a Bit Error Rate (BER) thanks to a WIFI (norm 802.11) digital transmission chain and we study the routing results obtained by the Dijkstra algorithm.
\end{abstract}

\section{INTRODUCTION}

Nowadays, an increasing interest is devoted to wireless network. Ad-hoc networks [1] represent an interesting alternative to current wireless networks, because we can deploy them quickly. Indeed, there are no centralized infrastructures to connect each mobile : they communicate directly each other. Nevertheless, this lack of infrastructures involve problems and notably in Ad-hoc network routing.

In this paper, we describe the Ad-hoc network simulator developed in our laboratory. It allows to determine the routing of the information based on the physical layer quality. Firstly, the simulator permit to create studied scenarios in different $3 \mathrm{D}$ realistic environments. Secondly, the simulation procedure based on a deterministic propagation tool and a given digital system is realized. First results are also given according to the $802.11 \mathrm{~b}$ norm [2].

At the end, we propose an optimized solution consisting in limiting the deterministic propagation computation. This one is based on the stationarity property of the channel, characterized by different maps of wide-band parameters. A segmentation algorithm applied on these maps allows to determine some areas where the channel impulse response is considered as constant. When a mobile moves in such an area, we can reuse the same impulse response without any new computation and thus, realize a significant gain in computation time. This gain will be evaluated in the final paper.

\section{AD-HOC NETWORK SIMULATOR : AdNS}

AdNS allows to simulate an Ad-hoc network at the physical layer. The first step consists in a scenario creation and the second one in the simulation execution.

\section{A. Creation of the scenario}

It consists in defining the initial position, route and speed of each mobile in a real 3D environment. Each trajectory can be cyclic or not and is composed of several points called checkpoints. Mobile's speed can be changed at each one. Fig. 1 illustrates a complete scenario with six mobiles in the campus of Poitiers's University.

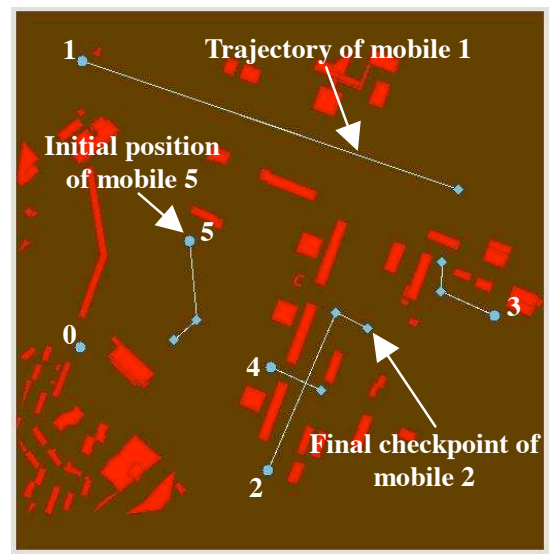

Fig. 1. AdNS scenario interface illustration

\section{B. Simulation and first results}

For the simulation step, we define the sample time (the elapsed time between two successive iterations during the simulation) and the number of iterations. Then, at each iteration, the simulator evaluates the real mobiles positions according to their trajectories, speeds and sample time. From these data, a 3D propagation tool based on a deterministic ray tracing software determines the links between each mobile. Each ones is characterized by the channel impulse response, as it is shown on the Fig. 2.
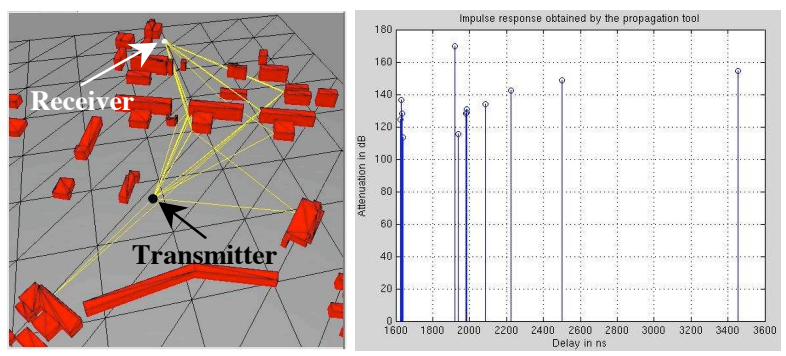

Fig. 2. Propagation tool and resulting impulse response 
These impulse responses are then used to compute the BER associated to the considered link and a particular digital systems. For the presented study, we consider WIFI systems based on the $802.11 \mathrm{~b}$ norm [1].

Thus, AdNS creates a connectivity graph corresponding to the scenario. Each node represents a mobile and each edge is quantify by the BER. From a particular node (seen as the source) the Dijkstra algorithm [3] determines at last the optimal routing path leading to a given destination for each iteration. Consequently, AdNS enables to follow the optimal routing evolution, as shown the Fig. 3. This particular simulation considers 8 iterations and a sample time equal to 10 seconds. We can notice the multi-hops aspect and the evolution of the optimal routing path between the source (mobile 0 ) and the destination (mobile 3 ). This last one depends on the delay spread of channel impulse response (Fig. 2) of each radio link.
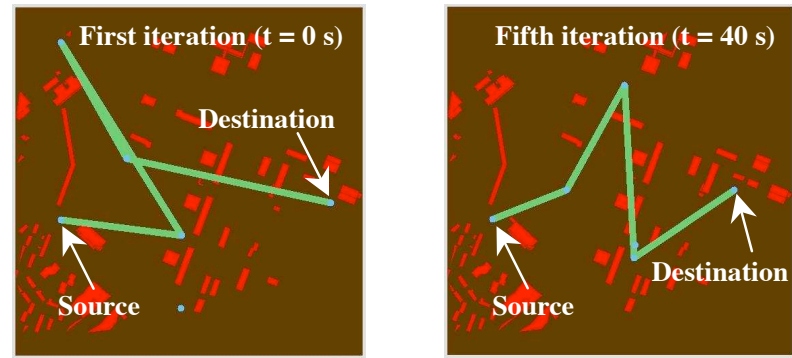

Fig. 3. Results for two different iterations

The computation time is directly linked to the determination of the channel characterization thanks to the propagation tool.

\section{CHANNEL CHARACTERIZATION OPTIMIZATION}

To minimize this computation time, we now present an optimization consisting in limiting the use of the deterministic propagation tool. It is based on the analysis of the wide-band parameters maps computed for a given transmitter location. For example, Fig. 4 (a) shows the evolution of the delay spread, computed from the simulated impulse responses, on a grid of receivers with a neighbouring step of 5 meters. A segmentation of this map based on an uniform quantification shows some homogeneous areas characterized by a constant values of delay spread. The Fig. 4 (b) illustrated 3 classes of delay spread (C1: low delay spread; C3: high delay spread).
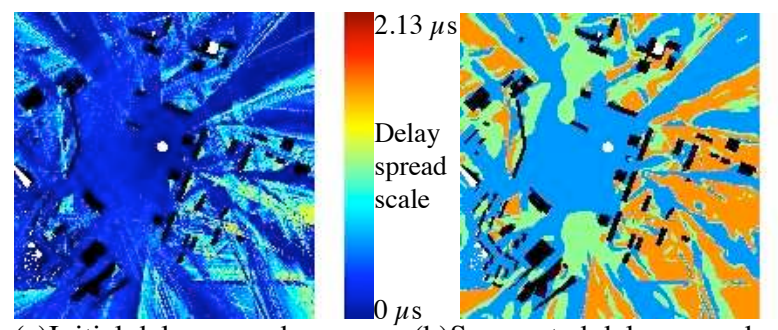

(a)Initial delay spread map

(b)Segmented delay spread map

Fig. 4. Delay spread maps

A statistical study has shown that these areas also correspond to a constant behaviour of the propagation channel in terms of impulse response. We can so consider these last ones as stationarity areas. Indeed, a small displacement of a mobile in such an area not necessitates a new propagation computation but just a reuse of the impulse response computed on the initial mobile location. From this way, a significant gain in computation time is provided.

Nevertheless, the map of stationarity areas shown on Fig. 4 (b) is obtained for a fixed transmitter, corresponding to a given iteration of the simulation step.

So, to solve this problem we pre-compute efficiently the different maps at each iteration and for each mobile location, according to a given scenario. This solution can be sufficient when the studied scenario consider a small number of iterations and mobiles. On the contrary case, a complementary solution could be developed. It consists in performing an additional study leading to determine the maximal displacement of the transmitter for which the initial impulse response can be used. Thus, maps of stationarity areas do not have to be computed at each iteration but only from a minimal displacement of the transmitter.

In the final paper, we will present a comparative study between classical statistical or deterministic approaches and our optimized semi-deterministic characterization in terms of routing results and computation time.

\section{FUTURE WORKS}

Future works of this study concern firstly a comparative study of different digital systems used in Adhoc networks like the others WIFI norms (802.11a and 802.11g) or HiperLan2. Secondly, we can simulated the behaviour of Ad-hoc network routing protocols, as AODV [4] or OLSR [5], in a real environment and compare theirs efficiencies. For this, we must considered the Ad-hoc network not only at the physical layer and realize the implementation of different routing protocols.

\section{ACKNOWLEDGEMENT}

This work is made thanks to the financial support of the "Région Poitou Charentes" (FRANCE).

\section{REFERENCES}

[1] P. Tortelier "Les réseaux Ad-hoc" Assemblée Générale / Séminaire $d u$ CNFRS (Comité Français de Radioéléctricité Scientifique), January 2003.

[2] IEEE Std 802.11b-1999, "Part 11: Wireless Lan Medium Access Control (MAC) and Physical Layer (PHY) specifications: Higher-Speed Physical Layer Extension in the $2.4 \mathrm{GHz}$ band", 1999.

[3] T.H. Cormen, C.E. Leiserson, R.L. Rivest and C. Stein Introduction to Algorithms, $2^{\text {nd }}$ ed., MIT Press and McGraw-Hill, 2001, Part IV, Chapter 25.

[4] C.E. Perkins and E.M. Royer, "Ad-hoc on-demand distance vector routing" Proc. Second annual IEEE workshop on mobile Computing Systems and applications, pp. 90-100, February 1999.

[5] T. Clausen, P. Jacquet, A. Laouiti, P. Muhlethaler, A. Qayyum and L. Viennot, "Optimized Link State Routing Protocol", IEEE INMIC, December 2001. 